\title{
Accountability for Project-Based Collaborative Learning
}

\author{
Abu-Hussain Jamal ${ }^{1}$, Mohammad Essawi ${ }^{1} \&$ Oleg Tilchin ${ }^{1}$ \\ ${ }^{1}$ Al-Qasemi Academic College of Education, Baqa El-Gharbieh, Israel
}

Correspondence: Oleg Tilchin, Academic College of Education P.O. Box 124, Baqa El-Gharbieh 30100, Israel. E-mail: otilchyn@yahoo.com

Received: December 15, 2013

Accepted: February 5, $2014 \quad$ Online Published: February 10, 2014

doi:10.5430/ijhe.v3n1p127

URL: http://dx.doi.org/10.5430/ijhe.v3n1p127

\begin{abstract}
One perspective model for the creation of the learning environment and engendering students' thinking development is the Project-Based Collaborative Learning (PBCL) model. This model organizes learning by collaborative performance of various projects. In this paper we describe an approach to enhancing the PBCL model through the creation of result-based accountability. Enhancing the model results in organizing PBCL as a two-phase process, creation of accountability for the students and their learning results, specific formation of a knowledge heterogeneous collaborative group, and the design of a learning assessment system. The teacher is accountable for teaching the subject through a sample project realized during the first phase of the process. Collaborative performance of group projects is realized in the second phase of PBCL. Student accountability for performance of determined project tasks is created on the basis of self-assessment of knowledge. A collaborative group is formed as a result of the coordination of personal accountabilities of students, taking into account teacher requirements providing students' shared accountability in performance of a group project. The learning assessment system includes: the initial formative assessments when studying a subject according to knowledge levels, inducing the building of higher-order knowledge; self-assessment that allows student accountability for learning outcomes; assessment knowledge built by students, owing to collaborative project performance; assessments when studying a subject; assessments of collaborative skills and accountability skills, and combined summative assessments. The approach promotes the collaborative building of knowledge, facilitation of knowledge sharing among students, and effective construction of higher-order thinking skills, accountability skills, and collaborative skills.
\end{abstract}

Keywords: Project-based collaborative learning, Accountability for learning, Complex assessment

\section{Introduction}

A modern organization functioning in a knowledge-based society requires that specialists have high professional intellect. Professional intellect is formed by knowledge and social intelligence (Quinn, Anderson \& Finkelstein, 1998; Goleman, 2007). Knowledge can be represented in four levels: know-what, know-how, know-why, care-why (Quinn, Anderson \& Finkelstein, 1998; Tiwana, 1999). Obviously, such specialists are the most suitable in terms of accountability for the achievement of needed results in an organization. Creating accountability for results promotes active and creative work (Connors \& Smith, 2011).

The four knowledge levels have their determined roles in education. Thus, the know-what level represents cognitive knowledge; the know-how level deals with practical problems of design based on a synthesis of knowledge; the know-why level refers to deep knowledge of complex cause-and-effect relationships; the care-why level represents self-motivated creativity. Know-why and care-why knowledge levels develop higher-order thinking skills. These skills are critical thinking, problem solving, and learning to learn (Dym et al., 2005).

Specialists are prepared by an academic institution with a student-centered learning environment favorable toward responsible learning and accountability for results (Garrison, 1992; Reeves, 2004; Krantz \& Soo Hoo, 2005; Doyle \& Taqq, 2008). The environment promotes goal setting and reflection, decision-making resulting in attainment of learning results, organizing feedback, critical thinking, and collaborative problem-based learning. Therefore, creating suitable result-based accountability can serve as leverage to acquire higher-order thinking skills in students.

Analysis of various methods, models and means of organization of teaching and learning tells us that project-based collaborative learning (PBCL) is a student-centered learning model providing the development of lifelong learning 
skills, thinking skills, and problem-solving abilities (Thomas, 2000; Felder \& Brent, 2001; Solomon, 2003; Barkley, Cross \& Howell, 2004; Savery, 2006; Ravitz, 2009; Bender, 2012). PBCL allows students to practice, gain, and improve soft skills such as leadership skills, social communication skills, and conflict resolution skills. These skills are difficult to improve through teaching materials alone.

PBCL is the most suitable model for creation of an environment that induces student accountability for learning resulting in building higher-order thinking skills. Students have to make decisions in order to attain positive results. Feedback furthers the quality of a project's outcome. Collaborative learning by doing occurs during joint realization of project tasks. Students drive their own learning through inquiry and collaborative work to create projects that correspond to their knowledge. Problem-based learning is promoted by the need to search for ideas and make decisions that create a positive result.

The central role in the creation of the PBCL environment is given to an instructor. The instructor should guide, facilitate, and stimulate the process of building higher-order thinking skills by creating accountability for learning results. A learning assessment system can support realization of the instructor's role. The system should keep students motivated and involved. Flexibility and complexity of an assessment provide relevance to desired learning outcomes. An assessment should promote accountability for learning results. Assessment should be a guided, dynamic, formative, and summative process (Shavelson, 2009).

The ultimate goal is development of an approach to enhance PBCL, directed towards forming and sustaining a learning environment which promotes knowledge building, construction of higher-order thinking skills, accountability skills, and collaborative skills through the creation of result-based accountability for students.

\section{Related Research}

The goal of teaching and learning based on the use of the PBCL model is to provide collaborative knowledge building, construction of higher-order thinking skills, and collaborative skills (Stahl, 2006; Scardamalia \& Bereiter, 2003; Weinberger et al., 2003). Productive ways to improve collaborative learning lead to the enhancement of the PBCL model through the creation of result-based accountability. It allows development of cognitive skills applicable to individual and social responsibility (Shavelson, 2009). The approaches, methods, and tools reviewed here are examined relative to various aspects of this process.

Markham (2012) notes that learning projects still concentrate on teaching content but not on acquiring skills and habits of investigation. To overcome this, the author suggests an approach to powerful projects, and specific management of project performance involving building higher- order knowledge through collaboration. Krantz \& Soo Hoo (2005) suggest a new approach to student-centered learning.

Krauss \&Boss (2013) created the project-based learning spiral. The spiral serves as practical guidance for teachers in creating critical thinking and needed learning experiences in PBCL. It helps instructors determine how projects can be expanded in scope, complexity, and impact.

Maltese (2012) stresses the need for a transition from a content-based system to a skills-based system. He affirms that engaging students in higher-level thinking by means of PBCL allows for higher-level thinking skills. The author emphasizes collaborative learning is both the strategy and the goal of PBCL. It serves as a means of student engagement in creative problem solving, and learning to work together. The author reveals skills of a group that function efficiently. These skills are communication, trust, shared leadership, and creative problem solving.

Stanton \& Fairfax (2007) have determined a productive collaborative environment. It should provide interdependence of the students on a project, individual accountability, face-to-face interaction, appropriate use of collaborative skills, and group processing. Debbie (2009) emphasizes the significance of group composition in PBCL. Krauss \& Boss (2009) describe a learning environment providing reflection and sharing within the project life cycle.

Wiliam (2011) describes strategies of formative assessment: clarifying, sharing, and understanding learning intentions and criteria for success; creating effective discussions, and project tasks that promote learning; providing feedback that drives learning; and activating individual and collaborative learning. Daradoumis, Xhafa \& Marquès (2002) suggest evaluating a project by means of two types of evaluation: formative and additive. The whole learning process is evaluated through formative assessment. Additive evaluation is assessment of documents and reports produced in various learning situations during project development.

Ellis \& Hafner (2008) propose the criteria for assessment of PBCL. According to these criteria, each student is evaluated based on the work of his team and his individual work as a member of the team. Ellis \& Hafner (2007) 
developed a tool for conducting three kinds of PBCL evaluation: assessment by an instructor, self-assessment, and peer assessments. Markham (2012) is quite right contending that creativity assessment is needed.

Individual accountability is a critical component of successful PBCL. Reeves (2004) discusses student-centered accountability systems. Stanton \& Fairfax (2007) propose enforcing individual accountability through forming productive collaborative groups providing team member compatibility, creating group roles, and use of peer assessments.

Shavelson (2009) emphasizes the need to provide mutual adjustment of formative function of accountability, conducive to changing the organization of teaching and learning, and the summative function of accountability directed towards determining the extent of accountability. Improvement of teaching and learning can be attained through coordination of assessment and accountability systems, learning outcomes, cognitive outcomes, and individual and social responsibility outcomes.

The analysis of publications discussed here shows that no complex approach exists for enhancing PBCL through the creation of student accountability for learning results. The proposed complex approach to enhancing PBCL through creating results-based accountability of students will further motivate productive learning due to:

- Promotion of knowledge building by students as a result of creating individual accountability for learning results based on self-assessment built knowledge, sharing accountability among students, and between a teacher and students

- Engendering the acquisition of higher-order thinking skills in students as a result of a guided formative assessment of student knowledge relative to different knowledge levels

- Facilitation of knowledge sharing among students due to formation of knowledge heterogeneous collaborative groups based on coordination of personal accountabilities among students

- Receiving feedback on learning as a result of complex summative assessments of students, including assessment of a student's knowledge by the instructor; assessment of studying of a subject; assessment of accountability skills; assessment of collaborative skills, and combined summative assessment.

\section{The Approach to Creating Accountability for Project-Based Collaborative Learning}

The aim of the approach is to provide effective studying of a subject by inducing the building of knowledge and higher-order thinking skills, and acquiring accountability skills and collaborative skills through the creation of accountability for learning results in the PBCL environment.

The proposed approach has the following procedures:

A. Organizing the teaching and learning of a subject

B. Creating accountability for performance of the project tasks

C. Forming knowledge-heterogeneous collaborative groups

D. Complex summative assessment of students after group projects are completed

\section{A. Organizing the teaching and learning of a subject}

Organization of the teaching and learning of a subject involves conducting a description of subject, development of a sample (type) project, setting formative assessments of studying of a subject, and organization of teaching and learning.

Description of a subject includes:

- A list of subject topics

- Course requirements from a student. After studying a subject, a student should know its concepts, get results by applying theoretical knowledge, explain cause-and-effect relationships, and form creative solutions.

- Need-to-know list of subject-relevant knowledge. Subject-relevant knowledge is cumulative knowledge that should be built by students during the course. Subject-relevant knowledge is characterized by knowledge levels. The knowledge levels are: know-what $\left(\mathrm{k}^{1}\right)$, know-how $\left(\mathrm{k}^{2}\right)$, know-why $\left(\mathrm{k}^{3}\right)$, care-why $\left(\mathrm{k}^{4}\right)$. Subject-relevant knowledge is aggregate topic-relevant knowledge, which is required knowledge of mentioned levels related to a subject topic.

Development of a sample project consists in the creation of a set of project tasks, determining the order of the task's performance, and establishment of correspondence between a subject and a sample project relative to the required knowledge. A set of project tasks should correspond with a set of subject topics, which means that one task of a 
sample project should correspond to each subject topic. Project-relevant knowledge (knowledge required for performance of the project) should be equal to subject-relevant knowledge.

\section{Example 1}

Knowledge relevant $\mathrm{j}$ topic is $\mathrm{K}_{\mathrm{j}}=<\mathrm{k}_{\mathrm{j}}{ }^{1}, \mathrm{k}_{\mathrm{j}}{ }^{2}, \mathrm{k}_{\mathrm{j}}{ }^{3}, \mathrm{k}_{\mathrm{j}}^{4}>$, where $\mathrm{j}=1, \ldots, \mathrm{n} ; \mathrm{n}$ is the quantity of subject topics. Knowledge relevant $\mathrm{j}$ project task is $\mathrm{K}_{\mathrm{j}}=<\mathrm{k}_{\mathrm{j}}{ }^{1}, \mathrm{k}_{\mathrm{j}}{ }^{2}, \mathrm{k}_{\mathrm{j}}{ }^{3}, \mathrm{k}_{\mathrm{j}}{ }^{4}>$, where $\mathrm{j}=1, \ldots$, n. Since each subject topic corresponds with one project task, then $\mathrm{n}$ is the quantity of project tasks.

Setting formative assessments when studying a subject includes setting the fixed assessments relative to different knowledge levels, subject topics, and tasks of a sample project. Setting the fixed assessments relative to different knowledge levels is a requirement for studying a subject. Thus, a requirement for development of higher-order thinking skills creates more assessment sizes for know-why and care-why levels. Formative assessments should be set to induce the building of accountability skills and collaborative skills.

\section{Example 2}

A fixed assessment of accountability skills equals $12 \%$. A fixed assessment of collaborative skills equals $10 \%$. The fixed assessments for studying of a subject according to knowledge levels are represented in Table 1.

Table 1. Fixed assessments for studying of a subject

\begin{tabular}{lll}
\hline The knowledge level number & The knowledge level name & Knowledge assessments \\
\hline 1 & know-what $\left(\mathrm{k}^{1}\right)$ & $6 \%$ \\
2 & know-how $\left(\mathrm{k}^{2}\right)$ & $18 \%$ \\
3 & know-why $\left(\mathrm{k}^{3}\right)$ & $24 \%$ \\
4 & care-why $\left(\mathrm{k}^{4}\right)$ & $30 \%$ \\
\hline
\end{tabular}

Setting of fixed assessments relative to subject topics and the tasks of a sample project are presented by Example 3 .

\section{Example 3}

If a subject includes 6 subject topics, then the fixed assessments of topic-relevant knowledge of a student relative to know-what, know-how, and know-why levels (Table 1) are equal to $1 \%, 3 \%$, and $4 \%$, accordingly. Since each task of a sample project corresponds with one subject topic, then fixed assessments of task-relevant knowledge (knowledge needed for performance of each project task) relative to know-what, know-how, and know-why levels are equal to $1 \%, 3 \%$, and $4 \%$, accordingly.

The fixed assessment of task-relevant knowledge relative to care-why level depends on the quantity of tasks for which a student of a study group should be held accountable. Thus, if the quantity of tasks for which a student is accountable is three, then the fixed assessment of task-relevant knowledge relative to care-why level equals $10 \%$.

The teaching and learning of a subject is organized into a two-phase process. The teaching and learning of a subject are realized through performance and completion of a sample project by a study group in the first phase. Continuation of subject study is realized through the students' collaborative performance of group projects in the second phase of this process. A teacher is accountable for teaching a subject in the first phase, and for facilitation and promotion of collaborative learning in students during the second phase.

\section{B. Creating accountability for performance of the project tasks}

Each student realizes self-assessment knowledge owing to the studying of a subject through a sample project. Then, a student compares his knowledge with the task-relevant knowledge needed for the group project. The project-relevant knowledge is equal to the sample project's relevant knowledge. As a result of comparison, the student determines possible tasks that he can perform and for which he would be accountable. According to his opinion, the determined tasks are the most suitable for successful performance (attaining result) because he has the needed knowledge. A student should accept accountability for a fixed quantity of tasks. 


\section{Forming knowledge heterogeneous collaborative groups}

The requirements for forming the collaborative group are determined by an instructor. The requirements are:

- A student may participate in only one group project

- All tasks of the project should be performed

- Maximal allowed quantity of students in a collaborative group is fixed

- The students of a collaborative group should participate in performance of all project tasks

- The students in a collaborative group should be accountable for performance of a fixed quantity of different project tasks

- All students in a collaborative group should be interdependent relative to the results of performance of project tasks for which they are accountable. It allows sharing of accountability.

The students of a study group discuss the possibility of collaborative performance of group projects by taking into consideration the requirements. During discussion, every student compares tasks for which he would be accountable with those tasks chosen by other students of a study group and the performance for which they would be accountable. The aim of comparison is to evaluate the possibility for collaboration of the student with other students during performance of a group project. As a result of compared analysis of tasks selected by students, the participants of knowledge heterogeneous collaborative groups for performance of the group projects are specified. Each collaborative group should satisfy the aforementioned requirements. The project tasks selected earlier by a student can be replaced by other tasks due to coordination with students of a study group.

\section{Example 4}

A sequence of the type of tasks $z_{1}, z_{2}, \ldots . ., z_{6}$ of the group project are determined. A number of the task reflects the priority of its performance. A study group contains 6 students. Maximal allowed quantity of students in the collaborative group is equal to two. Then, the quantity of collaborative groups must be equal to three. After self-assessments of knowledge and study group students' discussion, collaborative groups for performing group projects are formed. So, the fist collaborative group includes student $\mathrm{s}_{1}$, accountable for tasks $\mathrm{z}_{2}, \mathrm{z}_{4}, \mathrm{z}_{6}$, and student $\mathrm{s}_{2}$, accountable for tasks $z_{1}, z_{3}, z_{5}$. All aforementioned requirements for forming collaborative groups are observed. Thus, sharing accountability is built in since performance of the task $z_{2}$ by student $s_{1}$ requires prior performance of the task $\mathrm{z}_{1}$ by student $\mathrm{s}_{2}$, and so on. Every student makes the acquaintance of fixed assessments of studying a subject (Table1), accountability skills, and collaborative skills (Example 2).

\section{Complex summative assessment of students after completion of group projects}

Complex summative assessment of students by an instructor after completion of group projects includes assessment of a student's knowledge by the instructor; assessment of studying a subject; assessment of accountability skills; assessment of collaborative skills, and combined summative assessment.

Assessment of student knowledge built through collaborative performance of group projects is realized by the instructor through control questions with different knowledge levels and the examination of group projects. If a student answers questions of a certain knowledge level correctly it means he has knowledge at that level. The questions are related to subject topics. In this way the instructor evaluates correspondence between a student's knowledge and subject-relevant knowledge. The fixed assessments for various knowledge levels are taken into account. As a result, assessment by the instructor of a student's knowledge is made.

\section{Example 5}

The results of examination of student $s_{1}$ and $s_{2}$ of a collaborative group (Example 4) after performance of a group project are contained in Table2. Row names correspond to knowledge levels relative to project tasks. Lower and upper indices denote task numbers and knowledge levels accordingly. Fixed assessments of knowledge levels are shown. Column names correspond to student IDs. Knowledge of a certain level built by a student is marked at the intersection of a row and a column. If knowledge built by a student corresponds to a requirement, then the intersection of a row and a column is marked as " $v$ ". If knowledge does not satisfy the requirement completely, then the corresponding assessment is marked. If knowledge was not built by a student, then the intersection of the row and column is empty. The last row of Table 2 contains instructor assessments of student knowledge. 
Table 2. Assessments of student knowledge by an instructor after completion of group projects

\begin{tabular}{lll}
\hline Knowledge levels relative to project tasks & Student $\mathrm{S}_{1}$ & Student $\mathrm{S}_{2}$ \\
\hline $\mathrm{K}_{1}{ }^{1}(1 \%)$ & $\mathbf{V}$ & \\
$\mathrm{K}_{1}{ }^{2}(3 \%)$ & $\mathbf{V}$ & $\mathbf{V}$ \\
$\mathrm{K}_{1}{ }^{3}(4 \%)$ & & $\mathbf{V}$ \\
$\mathrm{K}_{1}{ }^{4}(10 \%)$ & $\mathbf{V}$ & $\mathbf{V}$ \\
$\mathrm{K}_{2}{ }^{1}(1 \%)$ & $\mathbf{V}$ & $\mathbf{V}$ \\
$\mathrm{K}_{2}{ }^{2}(3 \%)$ & $\mathbf{V}$ & \\
$\mathrm{K}_{2}{ }^{3}(4 \%)$ & $\mathbf{V}$ & \\
$\mathrm{K}_{2}{ }^{4}(10 \%)$ & $\mathbf{V}$ & $\mathbf{V}$ \\
$\mathrm{K}_{3}{ }^{1}(1 \%)$ & $\mathbf{V}$ & $\mathbf{V}$ \\
$\mathrm{K}_{3}{ }^{2}(3 \%)$ & & $\mathbf{V}$ \\
$\mathrm{K}_{3}{ }^{3}(4 \%)$ & & $\mathbf{V}$ \\
$\mathrm{K}_{3}{ }^{4}(10 \%)$ & $\mathbf{V}$ & $\mathbf{V}$ \\
$\mathrm{K}_{4}{ }^{1}(1 \%)$ & & $\mathbf{V}$ \\
$\mathrm{K}_{4}{ }^{2}(3 \%)$ & $\mathrm{V}$ & $\mathrm{V}$ \\
$\mathrm{K}_{4}{ }^{3}(4 \%)$ & $\mathbf{5 \%}$ & \\
$\mathrm{K}_{4}{ }^{4}(10 \%)$ & $\mathbf{V}$ & $\mathbf{V}$ \\
$\mathrm{K}_{5}{ }^{1}(1 \%)$ & $\mathbf{V}$ & $\mathbf{V}$ \\
$\mathrm{K}_{5}{ }^{2}(3 \%)$ & $\mathbf{2 \%}$ & $\mathbf{V}$ \\
$\mathrm{K}_{5}{ }^{3}(4 \%)$ & $\mathbf{5 \%}$ & $\mathbf{V}$ \\
$\mathrm{K}_{5}{ }^{4}(10 \%)$ & $\mathbf{V}$ & $\mathbf{V}$ \\
$\mathrm{K}_{6}{ }^{1}(1 \%)$ & $\mathbf{V}$ & $\mathbf{V}$ \\
$\mathrm{K}_{6}{ }^{2}(3 \%)$ & & \\
$\mathrm{K}_{6}{ }^{3}(4 \%)$ & $\mathbf{V}$ & \\
$\mathrm{K}_{6}{ }^{4}(10 \%)$ & $\mathbf{6 1}$ & $\mathbf{6 8}$ \\
$\mathrm{Kn}^{2}$ nowledge assessment by an instructor & $\mathbf{6 1}$ & \\
\hline
\end{tabular}

Assessment of the studying of a subject by students consists in an instructor's determination of their knowledge building results. Analysis is realized through assessment of a student's knowledge relative to the determined knowledge level.

Assessment of the studying a subject by a student relative to knowledge level is realized by comparison of assessment of the student's knowledge and a fixed assessment of subject study according to knowledge level. Such comparison is carried out by using the following formula:

where

$$
\mu_{\mathrm{j}}\left(\mathrm{s}_{\mathrm{i}}\right)=\left(\mathrm{g}_{\mathrm{j}}\left(\mathrm{s}_{\mathrm{i}}\right)-\mathrm{g}_{\mathrm{j}}\right) \backslash \mathrm{g}_{\mathrm{j}},-1 \leq \mu_{\mathrm{j}}\left(\mathrm{s}_{\mathrm{i}}\right) \leq 0
$$

$\mathrm{g}_{\mathrm{j}}\left(\mathrm{s}_{\mathrm{i}}\right)$ is an assessment of knowledge built by student $\mathrm{s}_{\mathrm{i}}$ relative to $\mathrm{j}$ knowledge level,

$\mathrm{g}_{\mathrm{j}}$ is a fixed assessment of a study subject for $\mathrm{j}$ knowledge level, $\mu_{\mathrm{j}}\left(\mathrm{s}_{\mathrm{i}}\right)$ is a coefficient of the success of studying a subject by student $\mathrm{s}_{\mathrm{i}}$ relative to $\mathrm{j}$ knowledge level.

The value of the coefficient of success characterizes proportional parts of different levels of built knowledge. Thereby, analysis of the results of knowledge building through PBCL should be realized by examination of values of the coefficient of success of studying a subject. Maximal value of the coefficient of success of studying a subject equals zero. It empowers evaluation of a lack of personal knowledge by comparing a calculated value of the coefficient of success of studying a subject relative to $j$ knowledge level with the maximal value of the coefficient of success.

\section{Example 6:}

The assessment of knowledge of the student $\mathrm{s}_{1}$ relative to the third knowledge level calculated on the basis of data from Table2 is $\mathrm{g}_{3}\left(\mathrm{~s}_{1}\right)=10 \%$. The fixed assessment of a study subject relative to this knowledge level is $\mathrm{g}_{3}=24$ (Table1). Hence, the coefficient of success of studying a subject by a student $\mathrm{s}_{1}$ relative to the third knowledge level according to formula (1) is $\mu_{3}\left(\mathrm{~s}_{1}\right)=-0.58$. Analogously, the assessment of knowledge of the student $\mathrm{s}_{2}$ relative to the third knowledge level is $g_{3}\left(s_{2}\right)=16 \%$. The coefficient of success of studying a subject by a student $\mathrm{s}_{2}$ relative to the third knowledge level is $\mu_{3}\left(\mathrm{~s}_{2}\right)=-0.33$. 
Comparison of value of coefficient $\mu_{3}\left(\mathrm{~s}_{1}\right)$ and the maximal value of the coefficient of success of studying a subject equal zero allows for the conclusion that student $\mathrm{s}_{1}$ has an essential lack of knowledge at this level. Comparison of calculated values of coefficients of success of student $s_{1}$ and student $s_{2}$ to the maximal value of the coefficient of success allows for the conclusion that student $\mathrm{s}_{2}$ is closer to achieving the purpose of studying a subject relative to the knowledge level.

Calculation of a coefficient of success in studying a subject by a student according to formula (1) can be carried out for aggregate of knowledge levels. For that, a fixed initial assessment of a study subject for several knowledge levels is determined as a sum of fixed assessments of knowledge for corresponding levels. Assessment of the studying of a subject relative to a chosen set of knowledge levels is determined as a sum of assessments for corresponding knowledge levels.

\section{Example 7:}

The assessment of knowledge of the student $s_{1}$ is relative to an aggregate of third and fourth knowledge levels calculated on the basis of data from Table2 is $\mathrm{g}_{3,4}\left(\mathrm{~s}_{1}\right)=35 \%$. The fixed assessment of a study subject relative to these knowledge levels is $\mathrm{g}_{3,4}=54 \%$ (Table1). Hence, the coefficient of success in studying a subject by a student $\mathrm{s}_{1}$ relative to these knowledge levels is calculated by formula (1) is $\mu_{3,4}\left(\mathrm{~s}_{1}\right)=-0.35$. Analogously, the assessment of knowledge of the student $\mathrm{s}_{2}$ relative to the knowledge levels is $\mathrm{g}_{3,4}\left(\mathrm{~s}_{2}\right)=46 \%$. The coefficient of success of studying a subject by a student $s_{2}$ relative to the knowledge levels is $\mu_{3,4}\left(\mathrm{~s}_{2}\right)=-0.15$. Comparison of calculated values of the coefficients of success of student $s_{1}$ and student $s_{2}$ allows to conclude that student $s_{2}$ has essentially more higher order knowledge.

The assessment of knowledge of the student $\mathrm{s}_{1}$ relative to all knowledge levels is $\mathrm{g}\left(\mathrm{s}_{1}\right)=61 \%$ (Table2). The fixed assessment of a study subject is $\mathrm{g}=78 \%$ (Table1). Hence, the coefficient of success of studying a subject by a student $\mathrm{s}_{1}$ calculated by formula (1) is $\mu\left(\mathrm{s}_{1}\right)=-0.22$. Analogously, the coefficient of success of studying a subject by a student $\mathrm{s}_{2}$ is $\mu\left(\mathrm{s}_{2}\right)=-0.13$. Comparison of calculated values of the coefficients of success of studying a subject by the students $s_{1}$ and $s_{2}$ allows to conclude that the results are close. Yet, according to aforementioned, student $s_{2}$ differed from student $\mathbf{s}_{1}$ by building higher order knowledge. It allows to conclude that student $\mathbf{s}_{2}$ is more successful in building higher-order thinking skills, and student $s_{1}$ is more successful in building knowledge at first and second levels.

Assessment of accountability skills is based on the next argument. For example, a student assumes accountability for the completion of determined project tasks. It induces the student to aspire toward creative solutions during performance of the project tasks for which he is accountable, and corresponds with the care-why level of knowledge. Hence, assessments of accountability skills should be determined through comparison of assessments in studying a subject relative to the care-why level of knowledge by students. The objective of comparison is to determine those students who obtained a maximal assessment. Then, the assessments of accountability skills are calculated proportionally to the assessments of studying a subject relative to the care-why level of knowledge on the basis of fixed assessment of accountability skills.

\section{Example 8:}

The fixed assessment of accountability skills is $12 \%$. This assessment is obtained by the student $\mathrm{s}_{2}$ since the assessment of studying a subject relative to the care-why level of knowledge by the student is maximal and equals $30 \%$ (Table 2). The assessment of studying a subject by the student $\mathrm{s}_{1}$ relative to care-why knowledge level is $25 \%$ (Table 2). Hence, the assessment of accountability skills obtained by the student $s_{1}$ equals $10 \%$.

Assessment of collaborative skills is determined based on comparison of assessments of studying a subject relative to know-how and know-why levels of knowledge by students during collaborative performance of group projects. The objective of the comparison is to determine those students who obtained a maximal assessment relative to these knowledge levels. Such assessment can serve as a measure of success of collaboration of a student with other students of the collaborative group, created by specificity of the collaboration group.

The collaborative group is knowledge heterogeneous owing to need of observance of the aforementioned requirement of sharing accountability for performance of the project tasks among members of the group. It fosters and facilitates knowledge sharing among students.

The assessments of students' collaborative skills, therefore, should be calculated proportionally to the assessments of studying a subject relative to know-how and know-why levels of knowledge on the basis of fixed assessment of collaborative skills. 


\section{Example 9:}

The fixed assessment of collaborative skills is $10 \%$. This assessment is obtained by the student $s_{2}$ since the assessment of study of a subject by the student relative to know-how and know-why levels of knowledge is maximal and equals $34 \%$ (Table 2). The assessment of study of a subject relative to these levels of knowledge by the student $\mathrm{s}_{1}$ equals $25 \%$ (Table 2 ). Hence, the assessment of collaborative skills obtained by the student $\mathrm{s}_{1}$ equals $7 \%$.

The combined summative assessments characterize outcomes of PBCL. These assessments are determined by summation of knowledge assessment as determined by an instructor and assessments of accountability skills and collaborative skills.

\section{Example 10:}

Results of calculating combined summative assessments of students are represented by the last row of Table 3 .

Table 3. Combined assessments of students

\begin{tabular}{lll}
\hline The kind of assessments & $\mathbf{S}_{\mathbf{1}}$ & $\mathbf{S}_{\mathbf{2}}$ \\
\hline Knowledge assessment by an instructor & 61 & 68 \\
Assessment of accountability skills & 10 & 12 \\
Assessment of collaborative skills & 7 & 10 \\
Combined summative assessment of students & 78 & 90 \\
\hline
\end{tabular}

\section{Conclusion}

Enhancing PBCL according to the proposed approach is provided by organizing PBCL as a two-phase process, creating accountability for students' learning results, specific formation of knowledge heterogeneous collaborative groups for projects' performance, complex and evaluation of learning results. A bond between result-based accountability and assessment is revealed. The active role of assessment in the bond is determined.

Organizing PBCL as a two-phase process provides sharing of result-based accountability between a teacher and students. Student accountability for results of determined project tasks' performance is created through self-assessments of their knowledge. Specificity of forming a collaborative group consists in the coordination of personal accountabilities of students and the necessity of observance of the requirements to form the collaborative group that are determined by an instructor. These requirements create shared student accountability for performance and completion of group projects and knowledge heterogeneity of the collaborative group.

An assessment system is designed. This system realizes coordination of formative assessments, self-assessments, and complex summative assessments. Peculiarity of the system consists in its aim to promote the building of knowledge and higher-order thinking skills, and acquiring collaborative skills and accountability skills.

The approach provides balance between academic competition and cooperation. The approach promotes the creation of personal results-based accountability and sharing accountability among students for performance results of a learning project, the stimulation and building of higher-order knowledge, facilitation of knowledge sharing among students, and acquiring collaborative skills and accountability skills through the creation of personal accountability for results in the performance of project tasks.

\section{References}

Barkley, E., Cross, K. \& Howell, M. (2004). Collaborative Learning Techniques: A Handbook for College Faculty (Paperback), Jossey-Bass, 1edition.

Bender W.N. (2012). Project-Based Learning: Differentiating Instruction for the 21st Century, Corwin.

Connors, R. \& Smith, T. (2011). Change the Culture Change the Game, Penguin Group Inc.

Daradoumis T., Xhafa F. \& Marquès J.M. (2002). A methodological framework for project-based collaborative learning in a networked environment, International Journal Cont. Engineering Education and Lifelong Learning, Vol. 12, Nos.5/6.

Debbie Richards. (2009). Designing Project-Based Courses with a Focus on Group Formation and Assessment, Journal ACM Transactions on Computing Education (TOCE), Volume 9, Issue1.

Doyle, T. \& Taqq, J. (2008). Helping Students Learn in a Learner-Centered Environment: A Guide to Facilitating Learning in Higher Education, Stylus Publishing.

Dym, C., Agogino, A., Eris, O., Frey, D., Leifer, L. (2005). Engineering Design Thinking, Teaching and Learning, Journal of Engineering Education, Volume 94, Issue1, $103-120$. http://dx.doi.org/10.1002/j.2168-9830.2005.tb00832.x 
EllisT., Hafner W. (2007). Assessing Collaborative, Project-based Learning Experiences:Drawing from Three Data Sources, In Proceedings of $37^{\text {th }}$ ACEE/IEEE Frontiers in Education Conference.

Ellis T., Hafner W. (2008). Building a Framework to Support Project-Based Collaborative Learning Experiences in an Asynchronous Learning Network, Interdisciplinary Journal of E-Learning and Learning Objects, Volume4.

Felder, R.M. \& Brent, R. (2001). Effective Strategies for Cooperative Learning, [Online] Available: http://www2.ncsu.edu/unity/lockers/users/f/felder/public/papers/CL

Garrison, D. R. (1992). Critical Thinking and Self-Directed Learning in Adult Education: An Analysis of Responsibility and Control Issues, Adult Education Quarterly, vol. 42 no. 3 136-148. http://dx.doi.org/10.1177/074171369204200302

Goleman, D. (2007). Social Intelligence: The New Science of Human Relationships, Bantam.

Krantz, M. \& Soo Hoo, B. (2005). Alternative Problem-based Collaborative Learning Model and Student Experiencies. In Silverman, Sh. \& Casazza, M. (2005). Partners for Innovation In Teaching and Learning: A Shared Responsibility, I Universe, Inc.

Krauss, J. I., Boss, S. K. (2009). Reinventing Project-Based Learning: Your Field Guide to Real-World Projects in the Digital Age, Amazon Digital Services, Inc.

Krauss. J. I., Boss, S. K. (2013). Thinking Through Project-Based Learning: Guiding Deeper Inquiry, Corwin; 1 edition.

Maltese, R. (2012). Project Based Learning, 25 Projects for $21^{\text {st }}$ Century Learning, Dog Ear Publishing.

Markham, T. (2012). Project Based Learning Design and Coaching Guide, Heart IQ Press.

Quinn J., Anderson P. \& Finkelstein S. (1998). Managing Professional Intellect, Harvard Business Review on Knowledge Management, Harvard Business School Press, pp. 181-205.

Ravitz, J. (2009). Introduction: Summarizing Findings and Looking Ahead to a New Generation of PBL Research. Interdisciplinary Journal of Problem-based Learning, 3(1). http://dx.doi.org/10.7771/1541-5015.1088

Reeves, B. D. (2004). Accountability for Learning: How Teachers and School Leaders Can Take Charge, Association for Supervision \& Curriculum Deve.

Savery, J. R. (2006). Overview of Problem-based learning: Definitions and Distinctions, The Interdisciplinary Journal of Problem-based learning, volume1, N1.

Scardamalia M., Bereiter C. (2003). Knowledge Building Environments: Extending the Limits of the Possible in Education and Knowledge Work, In Distefano A., Rudestam K.E., \& R. Silverman (eds.), Encyclopedia of distributed learning. Thousand Oaks, CA: Sage Publications.

Shavelson R. (2009). Measuring College Learning Responsibly: Accountability in a New Era, Stanford University Press.

Solomon, G. (2003). Project-Based Learning: A Primer. Technology and Learning, Vol 23, N6.

Stahl, Gerry. (2006). Group Cognition: Computer Support for Building Collaborative Knowledge (Acting with Technology), The MIT Press.

Stanton, P. \& Fairfax, D. (2007). Establishing Individual Accountability for Learning in an Exam-less, Group Project Course, Proceedings of the 2007 Middle Atlantic Section Fall Conference of the American Society for Engineering Education, pp. 1-9.

Thomas, J. W. (2000). A review of Research on Project-Based Learning, Supported by the Autodesk Foundation, [Online] Available: http://www.autodesk.com/foundation

Tiwana, A. (1999). The Knowledge Management Toolkit. Practical Techniques for Building a Knowledge Management System, Prentice Hall.

Weinberger, A., Reiserer, M., Ertl, B., Fischer, F. \& Mandl, H. (2003). Facilitating Collaborative Knowledge Construction in Computer-Mediated Learning with Structuring Tools (Research report No.158). Munich, Germany: Ludwig-Maximilians-University, Institute for Empirical Pedagogy and Pedagogical Psychology. Research report No. 158, February [Online] Available: http://epub.ub.uni-muenchen.de/266/1/FB_158.pdf

Wiliam, D. (2011). Embedded Formative Assessment, Solution Tree Press. 